\title{
A UTILIZAÇÃO DE CENARIOS COMO DIFERENCIAL NA ORGANIZAÇÃO: UMA PESQUISA BIBLIOGRÁFICA
}

Álvaro Costa Jardim Neto, Ivan Marcio Gitahy Junior, Jean Carlos Silva Santos

Universidade do Oeste Paulista - UNOESTE, Curso de Administração, Presidente Prudente, SP. E-mail: carlosjeanjc@hotmail.com

\section{RESUMO}

O futuro incerto e o estudo para conseguir vantagens competitivas frente as outras organizações vem fazendo com que as empresas tomem medidas cada vez mais drásticas, necessitando apresentar respostas rápidas para afrontar os desafios que são propostos e utilizar as oportunidades que o mercado oferece. Entretanto percebe-se que estas incertezas têm prejudicado a decisão de qual estratégia seguir diante do imprevisível. Posto isto, surge a teoria dos cenários apoiando cada decisão a ser tomada pelo administrador. Este trabalho propõe apresentar os principais métodos e o histórico de cenários no contexto geral. Desta forma, utilizando uma metodologia bibliográfica de pesquisa e com aspecto exploratório, buscou-se conhecer métodos de produção de cenários, o histórico e sua importância nas tomadas de decisões organizacionais. Sendo assim, conclui-se que a construção de cenários pode ser utilizada como diferencial competitivo e auxiliador no momento de definir as estratégias para a empresa.

Palavras-chave: Administração. Cenários. Prospecção. Estratégia. Métodos.

\section{THE USE OF SCENARIOS AS A DIFFERENTIAL IN THE ORGANIZATION: A BIBLIOGRAPHICAL RESEARCH}

\begin{abstract}
The uncertain future and the study to achieve competitive advantages before other organizations has been doing with companies increasingly drastic measures, requiring present quick answers to addressing the challenges that are proposed and use the opportunities that the market offers. However one can see that these uncertainties have affected the decision of which strategy to follow on the unpredictable. Having said that, there is the theory of the scenarios supporting every decision to be taken by the administrator. This paper proposes to introduce the main methods and the history of scenarios in the general context. In this way, using a bibliographic search methodology and exploratory aspect, sought to meet production methods, the history and its importance in organizational decision-making. Therefore, it is concluded that the construction of scenarios can be used as a competitive differentiator and supportive at the time of defining strategies for the company.
\end{abstract}

Keywords: Directors. Scenarios. Prospecting. Strategies. Methods. 


\section{INTRODUÇÃO}

As transformações do início do século XX conduziram o enredo não só mundo atual como também de décadas próximas a mudanças socioculturais e econômicas, conduzidas por avanços, cada vez maiores, na tecnologia e na ciência. É primordial conhecer aspectos de incertezas que rodeiam as perspectivas de cada um, tornando o desejo de conhecê-las e controlá-las cada vez maior, ou seja, uma aproximação do ser humano com a possibilidade de conhecer o futuro.

A partir deste ambiente, as decisões a serem tomadas devem se enquadrar em circunstâncias que são incertas e que possuem pouco conhecimento das consequências que estão por vir, tornando então a pesquisa sobre estes casos mais relevante acerca dos efeitos que obterá dessas decisões.

O gerenciamento de cenários é uma forma importante e utilizada em grande escala como apoio a estratégia para condução dos processos e com bases em suas informações é possível alterar bases dos processos com o objetivo de concluir as metas de maneira mais confiável a fim de concluir de maneira mais satisfatória.

Dentro de um processo decisório empresarial é essencial que as informações estejam concisas e claras, principalmente quando estas decisões estão ligadas às decisões em um futuro mais próximo ou ligado a um futuro remoto.

Portanto este artigo tem como objetivo apresentar a importância da aplicação de cenários para o planejamento organizacional para alcançar os objetivos da empresa, não somente no sentido de suporte das estratégias empresariais, mas também como apoio a criação de novos negócios, suporte no modelo de divulgação das informações, melhor entendimento de cada parte do ambiente em que a empresa se situa e como atuar em meio a atmosfera de incertezas em que a empresa se situa.

\section{RESULTADOS}

Diante do ambiente contemporâneo e das mudanças tecnológicas preeminentes, a discussão sobre a utilização de estudos tem se tornado fundamental em função da necessidade das empresas garantirem sua sobrevivência e se relacionarem com esse ambiente incerto de forma apropriada.

Desenvolver cenários sobre diversas possibilidades de futuro da condição as empresas se mobilizarem para confrontar e agir estrategicamente frente a essas mudanças temporais, ou seja, ela não estará refém do tempo, mas o utilizará como diferencial competitivo em comparação com outras organizações (POPCORN, 2002).

Conhecer o futuro não é um desejo novo, essa busca existe desde o começo da 
humanidade. Com o objetivo de ter mais conhecimento 0 homem procurava informações para que ele corresse menos risco em suas decisões, se mantendo seguro e precavendo de cada ameaça que poderia aparecer (MARCIAL; RUMBACH, 2002).

Com base em passagens históricas, 0 estudo sistemático de cenários apenas se inicia no fim da segunda Guerra Mundial onde países começaram a se posicionar em torno das questões ambientais, tendenciados a um aumento do medo fez com que a preocupação sobre a segurança aumentasse e diversas outras questões relacionadas ao futuro dos países começaram a tomar maior relevância nas discussões governamentais.

De acordo com Marcial \& Grumbach (2002, p. 27) a base para os estudos prospectivos nasceu através dos acontecimentos da Guerra Fria e a Reconstrução da Europa e do Japão:

A partir do pós-guerra, os especialistas em planejamento tentaram se afastar dos exercícios meramente especulativos e impor suas técnicas de previsão clássica baseadas em modelos matemáticos para a elaboração dos planejamentos

governamentais de médio e longo prazo. Apesar das preocupações em evitar uma catástrofe mundial, foram dois fatores conjunturais os principais motivadores do surgimento de novas metodologias que viabilizassem um melhor planejamento estratégico: a Guerra Fria e a reconstrução da Europa.

Segundo Godet (1993) o surgimento foi na década de 70 na França, onde filósofos como Gaston de Berger e Bertrand de Jouvenel utilizando um método de estudo de prospectivas feito pela DATAR (Delégation à L'Aménagement du Territoire e à L'Action Regionale), com objetivo de desenvolver o país regionalmente.

Na década de 70 os números de grandes empresas americanas que utilizavam a análise de cenários eram de aproximadamente 1000 empresas, onde a grande parte adotou esta ferramenta logo após o embargo do petróleo que descontrolou a visão que até então era estável.

Entretanto, depois de passado o choque em relação ao petróleo, a utilização de cenários novamente perdeu força nestas empresas, pois em alguns casos o seu alto valor foi considerado entrave para continuação da sua utilização.

Com a estabilidade politica e econômica da década de 80, o Brasil começou a ter um planejamento mais amplo, foi então que se iniciou a utilização de 
cenários no país (BUARQUE, 1998). Estimulado por esse modelo de planejamento, em 1996 foi lançado no Brasil um programa divulgado como "Brasil 2020" marcando o inicio da estimulação da pesquisa de cenários no país.

\section{METODOLOGIA}

A pesquisa se constitui através de análise de pesquisa bibliográfica, por se tratar de um tema exploratório. Segundo Gil (2002), as pesquisas exploratórias têm como objetivo primeiramente elucidar ideias e descoberta de intuições, portanto a pesquisa bibliográfica é composta por material já produzido e elaborado, ou seja, livros e artigos publicados.

Para Marconi e Lakatos (2007), a pesquisa com base em bibliografia não pode ser dita como repetição de um mesmo assunto ou uma reescrita sobre um mesmo assunto, mas é uma nova abordagem sobre um assunto que leva a novas conclusões inovadoras.

A abordagem desta pesquisa foi qualitativa, pois esta consegue diminuir a distância e aproximar a teoria e os dados e transformar em um só conteúdo, tem a capacidade de expressar os acontecimentos do mundo social, ou seja, é mais interpretativa (MAANEN, 1979).

\section{DISCUSSÃO}

Os benefícios da utilização de cenários são diversos, porém para desmistificar seus benefícios é necessário conhecer alguns métodos de projeção de cenários. De acordo com Schoemaker (1995), a utilização de cenários propicia benefícios melhores em situações que estão mais próximas com as condições de que:

- Há alto grau de incerteza com relação à capacidade de predizer o futuro ou corrigir rumos.

- $\quad$ Viveu-se um histórico marcado por surpresas desagradáveis e onerosas.

- $\quad$ o pensamento estratégico tem sido de baixa qualidade.

- Mudanças significativas no contexto ocorreram ou estão prestes a ocorrer.

- Há necessidade de uma nova perspectiva e linguagem comuns, sem perder de vista a diversidade.

- $\quad$ Coexistem fortes diferenças de opinião, e muitas delas têm mérito.

Diante disto, pode-se considerar que não há divergência entre essas empresas e grande parte das empresas, onde a utilização de cenários pode ser uma grande contribuição seja no setor ou área aplica, no suporte de ideias, apoio de decisões estratégias ou até mesmo no apoio a uma 
política de reestruturação adotada com base no cenário em que ela irá se encontrar.

Com base nos estudos de Bethlem (2002) e Marcial e Grumbach (2002), pode-se considerar que os métodos com passos mais precisos concisos, em seus conceitos, de acordo com a filosofia abordada são: Michel Godet, Peter Schwartz; Michael Porter e Raul Grumbach.

Os métodos apresentados buscam prospectar e analisar o macroambiente, e perspectivas vindouras a fim de definir um futuro para a organização elaborando estratégias que definam como se adequar ao cenário criado.

Toda essa construção torna-se mais relevante ao se aplicar os métodos citados acima e que serão destacados a seguir.

\section{Peter Schwartz}

Peter Schwartz (2000) foi o criador da Global Business Network (GBN), empresa norte americana, que desde sua fundação em 1988 esta totalmente voltada para formulação de cenários.

Schwartz descreve sua metodologia em oito etapas que estão totalmente interligadas:

- Identificação da questão principal

- Identificação das principais forças do ambiente local
- Identificação das forças motrizes

- Hierarquizar por importância e Incerteza

- Seleção das lógicas dos cenários

- Descrição dos cenários

- Análise das implicações e opções

- Seleção dos principais indicadores e sinalizadores

Utilizar indicadores como base nos cenários, possibilita a seleção de diversas variáveis que a empresa deve monitorar, onde a escolha baseada nos estudos de cenários leva a organização a identificar em qual aspecto necessita ser trabalhado melhor e o que deve ser monitorado frente ao impacto que podem causar dependendo do comportamento adotado.

O acompanhamento de cada variável é importante para que possa demonstrar através das informações obtidas cada uma das mudanças ambientais, dando poder de administração frente ao cenário apresentado, dando um diferencial ou até mesmo ganhando valorização superior a concorrência.

\section{Michael Porter}

O empenho de Porter no contexto de cenários está totalmente ligado a indústria, seu objetivo era marcar a relevância do 
método para essa área a fim de apresentar este conceito com uma aplicação ampla, pois a sua utilização serviria para perfeito em circunstancias em que o ambiente é de incertezas futuras e a necessidade de estratégias competitivas cada vez maior.

Porter (1992) estabelece 8 fases ao qual se deve seguir para produção de cenários, onde os estudos de mercado e as variáveis do macroambiente são criteriosamente analisadas a fim de produzir um diagnostico altamente preciso. As fases são:

- $\quad$ Propósito do estudo

- $\quad$ Estudo histórico e da situação atual

- Identificação das incertezas críticas

- Comportamento futuro das variáveis

- Análise de cenários e consistência

- $\quad$ Concorrência

- Elaboração das histórias de cenários

- $\quad$ Elaboração das estratégias competitivas

\section{Michel Godet}

Para Godet (2000), a análise de cenários e o planejamento estratégico baseado nesta análise é como enfrentar o desafio de antecipar os fatos antes de agir.
Em seus estudos declarava-se favorável a junção da estratégia e da utilização de cenários, firmando-se como um dos principais defensores da utilização de cenários, onde juntamente com Marc Giget desenvolveu o conceito de árvore de competências.

Segundo Marcial e Grumbach (2002), os métodos apresentados por Godet em seus estudos nos levam precisamente a 6 etapas que se se adequam a qualquer forma de organização, sendo que a sua utilização se torna favorável a ponto de dar um suporte completamente amplo nas decisões e estratégias a serem tomadas, se aplicado corretamente. Quanto às etapas, são elas:

- Delimitação do sistema e do ambiente

- Análise estrutural do sistema e do ambiente

- Seleção dos condicionantes do futuro

- Geração de cenários alternativos

- $\quad$ Testes de consistência, ajuste e disseminação

- Opções estratégicas e planas sobre monitoração estratégica

Entretanto, é necessário que em todas as etapas do processo, haja acompanhamento e uma analise de cada etapa desenvolvida, a fim de que não se perca nenhuma informação, não ocorra 
ruídos ou entraves que atrapalhe o resultado final apropriado, sendo uma analise completamente correta e o cenário apresentado seja o mais preciso.

\section{Raul Grumbach}

Dos estudos de Grumbach nasce um método para construção de cenários baseado em apenas 4 etapas, onde a sua utilização nos leva a construir cenários prospectivos a fim de definir estratégias que sejam plausíveis a construção do futuro da organização.

Marcial (1999), demonstra que os métodos de elaboração de Grumbach para cenários baseia-se na definição que existem diversas possibilidades de futuro possíveis e que o futuro não será, na sua essência uma base formada do passado.

Neste intuito, Grumbach define quatro fases para definir os cenários:

- A definição do problema

- A pesquisa ou o diagnóstico estratégico

- O processamento dos dados

- $\quad$ Sugestões sobre o que foi construído

\section{CONCLUSÃO}

A pesquisa teve o objetivo de demonstrar o histórico dos cenários prospectivos, apresentar alguns dos modelos, com suas fases, utilizados e contextualizá-los com o planejamento estratégico para as organizações.

Desta forma, com foco no contexto organizacional, é necessário a observação dos métodos para que possam ser analisados, comparados e discutidos, com o intuito de oportunizar ao leitor a possibilidade de escolha do método que julgar será mais apropriado para sua utilização.

O estudo de cenário é completamente instigante e versátil, pois eleva a capacidade de motivação de uma equipe e reintegra valores competitivos a organização, dando oportunidades de inovar, formular um portfólio de estratégias organizacionais e por fim uma visão mais clara do futuro que é demasiadamente incerto.

Torna-se importante também o estudo, pois observa-se uma lacuna nos estudos teóricos que demonstrem e desmitifique esta ferramenta tão precisa e de alta relevância. Cabe salientar que tal estudo é relevante já que antecipa os cenários propostos no futuro da empresa, auxiliando em uma orientação mais adequada para se definir estratégias fazendo com que as empresas tenham condições de inovar se preparar de forma consciente para algo que é inesperado. 


\section{REFERÊNCIAS}

BETHLEM, A. Estratégia empresarial: conceitos, processos e administração estratégica. 4. ed. São Paulo: Atlas, 2002.

BUARQUE, S. C. Experiências Recentes de Elaboração de Cenários do Brasil e da Amazônia Brasileira. Revista Parcerias Estratégicas, v. 1, n. 5, set. 1998

GIL, A. C. Como elaborar projetos de pesquisa. 4. ed. São Paulo: Atlas, 2002.

GODET, M. A. Manual de prospectiva estratégica: da antecipação a acção. Lisboa: Dom Quichote, 1993.

MAANEN, J. V. Reclaiming qualitative methods for organizational research: a preface. v.24. In Administrative Science Quarterly, 1979.

MARCIAL, E. C.; GRUMBACH, R. J. S. Cenários prospectivos: como construir um futuro melhor. Rio de Janeiro: FGV, 2002.

MARCONI, M. A.; LAKATOS, E. $M$. Fundamentos de metodologia científica. São Paulo: Atlas, 2007
. Técnicas de pesquisa: planejamento e execução de pesquisas, amostragens e técnicas de pesquisa, elaboração, análise e interpretação de dados. 5. ed. São Paulo: Atlas, 2002.

PORTER, M. E. Estratégia competitiva: técnicas para análise de indústrias e da concorrência. Rio de Janeiro: Campus, 1992.

POPCORN, F.; HANFT. O dicionário do futuro: as tendências e expressões que definirão nosso comportamento. Rio de Janeiro: Campus, 2002.

SCHOEMAKER, P. J. H. Scenario Planning: A Tool for Strategic Thinking. Sloan Management Review, Winter 1995.

SCHWARTZ, P. A arte da visão de longo prazo: planejando o futuro em um mundo de incertezas. São Paulo: Best Seller, 2000.

Recebido para publicação em 12/08/2015

Revisado em 04/09/2015

Aceito em 08/09/2015 